\title{
Determination of oxidative and occupational stress in palliative care workers
}

\author{
Ángela Casado ${ }^{1, *}$, Alberto Castellanos ${ }^{2}$, \\ Ma Encarnación López-Fernández ${ }^{1}$, Rocío Ruiz ${ }^{1}$, \\ Eulalia López Imedio ${ }^{3}$, Carmen Castillo ${ }^{2}$ and \\ Ana María Fernández-Nieto ${ }^{2}$ \\ ${ }^{1}$ Departamento de Fisiopatología Celular y Molecular, \\ Centro de Investigaciones Biológicas (CSIC), Ramiro de \\ Maeztu, Madrid, Spain \\ ${ }^{2}$ Servicio de Salud Laboral, Hospital General Universitario \\ Gregorio Marañón, Doctor Esquerdo, Madrid, Spain \\ ${ }^{3}$ Unidad de Cuidados Paliativos, Hospital General \\ Universitario Gregorio Marañón, Doctor Esquerdo, Madrid, \\ Spain
}

\section{Abstract}

Background: In previous work, we demonstrated that some occupational workers in stressful conditions can have increases in several markers of oxidative stress when compared to other workers. We investigated two antioxidant enzymes, superoxide dismutase (SOD) and catalase (CAT) activities, and malondialdehyde (MDA) concentrations, according to demographics, lifestyle and occupational parameters in palliative care unit workers, and analyzed the relationship with occupational burnout.

Methods: Fifty-two palliative care unit workers and 50 gender- and aged matched healthy individuals as controls were surveyed. Spectrophotometric and high-pressure liquid chromatography methods were used for biochemical determinations.

Results: No significant variation with respect to gender were detected with respect to SOD and CAT activities, MDA concentrations or occupational burnout. MDA concentrations increased with age in controls and palliative care unit workers, and we observed significant differences in MDA between controls and palliative care unit workers for all age groups. Significant variation in MDA concentrations were detected between unmarried $(287.22 \pm 8.31 \mathrm{nmol} / \mathrm{mg}$ hemoglobin) and married individuals $(317.18 \pm 6.24 \mathrm{nmol} / \mathrm{mg}$ hemoglobin), but not with respect to divorced individuals $(288.41 \pm 5.64 \mathrm{nmol} / \mathrm{mg}$ hemoglobin). Significant differences were detected between smokers and non-smokers for SOD, CAT and MDA, but not for alcohol, coffee, tea or cola consumption. Significant differences were seen in MDA con-

*Corresponding author: Ángela Casado, Departamento de Medicina Celular y Molecular, Centro de Investigaciones Biológicas (CSIC), Avda. Ramiro de Maeztu, 9, 28040 Madrid, Spain

Phone: +34 91 8373112, Fax: + 3491 5360432,

E-mail: acasado@cib.csic.es

Received May 5, 2010; accepted August 4, 2010; previously published online December 14, 2010 centrations between those who frequently practice some kind of sport (280.59 $\pm 7.62 \mathrm{nmol} / \mathrm{mg}$ hemoglobin) and those who never practice any kind of sport $(299.12 \pm 8.09 \mathrm{nmol} / \mathrm{mg}$ hemoglobin), and between those who frequently ate fruit and greens $(291.05 \pm 8.11 \mathrm{nmol} / \mathrm{mg}$ hemoglobin) and those who never eat fruit and greens $(316.31 \pm 7.42 \mathrm{nmol} / \mathrm{mg}$ hemoglobin). SOD activity and MDA concentrations are higher in palliative care workers who work the evening and night shifts $(\mathrm{p}<0.01)$, and these workers also show significantly higher levels of stress.

Conclusions: Our findings suggest that oxidative stress, occupational stress and occupational burnout levels are similar in men and women. Occupational stress increases oxidative stress levels probably as a response to increased generation of reactive oxygen species. Working during the evening and night shifts increases oxidative levels and burnout levels.

Keywords: antioxidant enzymes; burnout; lipid peroxidation; malondialdehyde; occupational stress; oxidative stress; palliative care.

\section{Introduction}

Reactive oxygen species (ROS) are formed in both physiological and pathological conditions in the cytosol, mitochondria, lysosomes, peroxisomes and plasma membranes (1). Their concentrations can be increased in situations, such as occupational stress (2-4). These ROS are extremely reactive and unstable chemical species and can react with proteins, lipids, carbohydrates and nucleic acids in the body. The reactions of ROS with macromolecules can lead to deoxyribonucleic acid (DNA) mutation, changes in the structure and function of proteins, and peroxidative damage to cell membrane lipids (5).

The membranes of mammalian cells contain large amounts of polyunsaturated acid which can undergo peroxidative injury. This oxidation of membrane lipids causes increased permeability of the cell membranes (6). Lipid peroxidation is a complex process which involves the formation and propagation of lipid radicals, a rearrangement of double bonds in unsaturated lipids, and the eventual destruction of membrane lipid. This process produces a variety of breakdown products including alcohols, ketones, aldehydes and ethers (7). Malondialdehyde (MDA) is the most abundant aldehyde resulting from lipid peroxidation. Thus, this aldehyde can be considered a marker of the lipid peroxidation, and increased concentrations of MDA are indicative of high oxidative stress (8). 
The biological effects of these highly reactive compounds are controlled in vivo by a wide spectrum of antioxidative defense mechanisms. Enzymes for preventing oxidative damage include superoxide dismutase (SOD), catalase (CAT), glutathione peroxidase (GPx), and glutathione reductase (GR), the latter which is essential for the maintenance of glutathione concentrations. Non-enzymatic antioxidants are defined in two phases: lipophylic (vitamin E, carotenoids, melatonin, etc.) and water soluble (vitamin $\mathrm{C}$, glutathione, uric acid, etc.). Three antioxidant vitamins, A, C and E, provide defense against oxidative damage.

Stress has been the focus of science, research and practical medicine for many decades (9). Stress is an adaptive response that prepares the organism for a threatening situation. It induces strain upon both emotional and physical endurance, which has been considered a basic factor in the etiology of a number of diseases (10-12). Stress as a concept describes the effects of psychosocial, occupational work and environmental factors on physical or mental well-being.

Occupational burnout is a complex phenomenon that has gathered significant attention among researchers over the last decade. Maslach and Jackson (13) provide a multifaceted conception of burnout, consisting of three sequential components that are the results of chronic stress. The first stage is emotional exhaustion (EE), where individuals feel emotionally overwhelmed by the demands of others. The second stage, depersonalization (DP), occurs by inappropriately attempting to cope with exhaustion. This stage is characterized by feelings of detachment and dehumanization. The final stage is a decreased sense of inadequacy, personal failure, and feelings of poor professional self-esteem.

Occupational stress is prevalent in work areas where there is much contact with distressed or dependent members of the public, and in people who work in intensive and palliative care units and emergency departments. The health professionals at risk include physicians, nurses, social workers, dentists, care providers in oncology, emergency service staff members, and mental health workers $(2-4,14,15)$.

For this reason, we tested the hypothesis that a direct relationship exists between oxidative stress (determined by antioxidant enzyme activities and MDA concentrations) and occupational stress [estimated by elements of the Maslach Burnout Inventory (MBI)] and burnout scores in workers in a palliative care unit.

\section{Materials and methods}

\section{Human subjects}

This study was reviewed and approved by the Superior Council of Scientific Investigations in Madrid (Spain) and by the Ethical Committee of Clinical Investigation of Gregorio Marañón Hospital in Madrid (Spain). The study was performed in accordance with the Ethical Standards outlined in the 1975 Declaration of Helsinki, as revised in 1983 and 1996.

The study sample consisted of 52 workers of a Public Health Services in Madrid (Spain) in a palliative care unit (23 men and 29 women). We also analyzed 50 age-matched healthy individuals (24 men and 26 women) as controls. Five age groups were established:
$<20$ years; 21-30 years; 31-40 years; 41-50 years; and 51-60 years. All subjects in the sample and the control group were residents of the same geographic area at the time of the study. All subjects were in good health and none were taking any product potentially interfering with antioxidant status (vitamins or minerals). Each participant gave informed consent prior to their inclusion in the study.

Subjects were given a questionnaire to obtain the following information:

- Sociodemographic parameters: gender, age, place of birth, residence, marital status and number of children.

- Lifestyle: balanced and healthy diet, exercise, smoking, consumption of alcohol, coffee, tea or coke.

- Occupational factors: qualifications and assigned task, long professional experience, work shifts (morning, evening, night), professional category, working conditions, relationship with other members of the staff, amount of work.

\section{Blood sampling}

Blood samples were obtained from the cubital vein. Fresh blood $(5 \mathrm{~mL})$ was collected into vacutainer tubes that contained lithium heparin and stored at $0-4^{\circ} \mathrm{C}$. All assays were performed within $24 \mathrm{~h}$ of collection.

\section{$\mathrm{Cu} / \mathrm{Zn}$ superoxide dismutase (SOD1) activity determination}

$\mathrm{Cu} / \mathrm{ZnSOD}$ (SOD1) activity was measured in red blood cells. $0.1 \mathrm{~mL}$ of blood was hemolyzed using $0.9 \mathrm{~mL}$ of ice-cold water $\left(0-4^{\circ} \mathrm{C}\right)$. The hemoglobin was removed by adding $0.25 \mathrm{~mL}$ of chloroform and $0.5 \mathrm{~mL}$ of ethanol, followed by vigorous mixing. The mixture was centrifuged at $18,000 \mathrm{~g}$ for $60 \mathrm{~min}$. The clear supernatant was used for the SOD assay. The assay was performed using the method of Minami and Yoshikawa (16), based on the inhibition of SOD1 by nitroblue tetrazolium (NBT) which is produced by superoxide radicals generated by autoxidation of pyrogallol. The rate of inhibition of the SOD reaction by SOD1 was calculated according to the definition of McCord and Fridovich (17).

\section{Catalase activity determination}

CAT activity was measured in hemolysate by the method of Aebi (18). The hemoglobin solution was obtained from fresh red blood cells. Heparinized blood samples were centrifuged at $2500 \mathrm{~g}$ for $10 \mathrm{~min}$, and as much of the plasma then removed. The remaining red blood cells were washed three times with $0.9 \% \mathrm{NaCl}$ solution, and subsequently hemolyzed by the addition of distilled water. Decomposition of the substrate, $\mathrm{H}_{2} \mathrm{O}_{2}$, was measured using an UVVIS spectrophotometer (Uvicon 810, Kontron, Zurich, Switzerland) at $240 \mathrm{~nm}$. The activity was expressed as the K-rate constant of the first order reaction, as defined by Aebi, per gram of hemoglobin.

\section{Malondialdehyde determination}

MDA concentrations were measured in erythrocytes by the method of Bull and Marnett (19). Blood was centrifuged at $2500 \mathrm{~g}$ for $10 \mathrm{~min}$ and as much of the plasma then removed. Erythrocytes were washed three times with $0.9 \% \mathrm{NaCl}$ solution and subsequently hemolyzed by the addition of distilled water. The supernatant solution was diluted by the addition of acetonitrile $(\mathrm{v} / \mathrm{v})$, followed by vigorous mixing. The mixture was centrifuged at $3000 \mathrm{~g}$ for $5 \mathrm{~min}$. 
The supernatant solution was filtered $(0.2 \mu \mathrm{m}$ pore-diameter membrane).

High-pressure liquid chromatography (HPLC) was performed using a HPLC (Pharmacia LKB Bromma model 2151, Sweden) equipped with a LKB Bromma 2151 model UV diode array detector and ChromJet integrator Spectra-Physics data processor (Production Engineering Medical Equipment Division, Denver, CO, USA) which enabled the peak purity to be analyzed. An ODS Hypersil column $(25 \mathrm{~cm} \times 4.6 \mathrm{~mm}, 5 \mu \mathrm{m})$ (Shandon Scientific Ltd, Runcorn, Cheshire, UK) was used as the stationary phase. The chromatographic conditions were: mobile phase $\mathrm{PO}_{4} \mathrm{HNa}_{2}$ and myristyltrimethylammonium bromide buffer $(\mathrm{pH} 7.4) /$ acetonitrile; flow rate, $0.4 \mathrm{~mL} / \mathrm{min}$; UV detection, $268 \mathrm{~nm}$; chart speed was $0.5 \mathrm{~cm} / \mathrm{min}$; attenuation six; temperature, ambient; and injection volume, $10 \mu \mathrm{L}$.

The column was equilibrated at the beginning of each daily series of measurements with at least $50 \mathrm{~mL}$ of the eluant. The MDA peak in the chromatogram was identified by comparison with a reference chromatogram of freshly prepared free MDA. The concentration of MDA was calculated from the area, based on a calibration chromatogram performed with a standard solution of MDA prepared by acid hydrolysis as described by Esterbauer et al. (20).

\section{Hemoglobin concentration determination}

Hemoglobin concentration was determined using the cyanmethemoglobin method (21). Blood was mixed with Drabkin's solution, a solution that contains potassium ferricyanide and potassium cyanide. The potassium ferricyanide oxidizes the iron in the hemoglobin forming methemoglobin. Then, potassium cyanide combines with methemoglobin to form cyanmethemoglobin which is a stable color pigment and can be read photometrically at $540 \mathrm{~nm}$. The concentration was expressed as $\mathrm{g} / 100 \mathrm{~mL}$.

\section{Burnout determination}

To measure burnout, a Spanish version of the MBI (13), adapted to sanitary staff by Oliver (22) was used. This is a 22-question instrument designed by Maslach and Jackson. Each question consists of a sentence with four alternative answers in which only one can be chosen. A different punctuation from one to four is assigned to each of the four possible answers. The final punctuation is obtained by adding the results of all the questions. This punctuation is used to measure the three stages of burnout. The first stage, EE, consists of nine questions $(1-3,6,8,13,14,16,20)$. The second stage, DP, was assessed by five questions $(5,10,11,15,22)$. The final stage, reduced personal accomplishment (RPA), was measured by eight questions $(4,7,9,12,17-19,21)$. The scores for each of the three stages of burnout were the total summation of the scores for the questions related to each area. A high score for EE or DP indicated high levels for these stages of burnout. For the third stage, personal accomplishment, low scores demonstrated a low-level of personal accomplishment, and thus indicated a high-level of this type of burnout.

\section{Statistical analysis}

Data were processed using standard statistical software (SPSS 10.2, SPSS Inc, Chicago, IL, USA). Results are expressed as the mean \pm standard deviation. The distribution of the groups was analyzed using the Kolmogorov-Smirnov test. As both groups showed a normal distribution, parametric statistical methods were used. For comparison of the groups, Student's t-test and analysis of variance (ANOVA) were performed. To assess significance, F-ratios obtained by ANOVA, the Bonferroni post-hoc test was used. Differences were considered significant at $\mathrm{p}<0.05$.

\section{Results}

\section{Sociodemographic parameters}

No significant variation with respect to gender were detected in SOD activity $(4.38 \pm 0.11 \mathrm{U} / \mathrm{mL}$ in blood from males vs. $4.27 \pm 0.12 \mathrm{U} / \mathrm{mL}$ in blood from females). These results agree with those obtained in a Spanish population (23). No significant differences were observed for different age groups (workers and controls). No significant variations with respect to gender were detected in CAT activity, expressed as mean \pm standard deviation $(223.87 \pm 5.91 \mathrm{k} / \mathrm{g}$ of hemoglobin in males vs. $229.10 \pm 7.78 \mathrm{k} / \mathrm{g}$ of hemoglobin in females). These results agree with those obtained in a Spanish population (24). Significant differences were observed (Table 1) for different age groups in workers in a palliative care unit, but not between workers and controls $(227.23 \pm 5.08 \mathrm{k} / \mathrm{g}$ of hemoglobin vs. $227.91 \pm 8.15 \mathrm{k} / \mathrm{g}$ of hemoglobin).

No significant variations with respect to gender were detected in MDA concentrations (345.46 $\pm 8.76 \mathrm{nmol} / \mathrm{mg}$ hemoglobin in males vs. $351.42 \pm 6.92 \mathrm{nmol} / \mathrm{mg}$ hemoglobin in females). These results agree with those obtained in a Spanish population (25). With respect to age, the group of those $<20$ years of age was used as the reference. As can be see in Table 2, MDA concentrations increase with age in both the control groups and in workers in palliative care. However, significant differences were found between the control group and workers in a palliative care unit for all age groups.

With regard to marital status (Table 3), significant variation in MDA concentrations were detected between unmarried $(285.64 \pm 7.91 \mathrm{nmol} / \mathrm{mg}$ hemoglobin) and married workers $(319.28 \pm 6.15 \mathrm{nmol} / \mathrm{mg}$ hemoglobin) but not with respect to those who were divorced $(289.04 \pm 5.88 \mathrm{nmol} / \mathrm{mg}$ hemoglobin). No significant differences in SOD and CAT activities and MDA concentrations were observed (Table 3) in relationship with those with children or to the number of

Table 1 Analysis of variance for CAT activity according to age.

\begin{tabular}{llrr}
\hline Source & Sum of squares & Df & Mean square \\
\hline Between groups & 434.856 & 4 & 108.714 \\
Within groups & 364.590 & 45 & 8.112 \\
Total (corr.) & 798.143 & 49 & $0.0002^{\text {a }}$ \\
\hline
\end{tabular}

aDenotes a statistically significant difference. Df, degree free. 
Table 2 MDA concentrations in palliative care workers and controls.

\begin{tabular}{|c|c|c|c|c|}
\hline & \multicolumn{2}{|c|}{ Palliative care workers } & \multicolumn{2}{|c|}{ Controls } \\
\hline & No. & $\mathrm{X} \pm \mathrm{DS}$ & No. & $\mathrm{X} \pm \mathrm{DS}$ \\
\hline$<20$ years & 6 & $283.79 \pm 6.59^{\mathrm{a}, \mathrm{b}}$ & 7 & $266.58 \pm 6.32^{\mathrm{c}}$ \\
\hline $20-29$ years & 15 & $335.10 \pm 4.08^{\mathrm{a}, \mathrm{b}}$ & 16 & $284.61 \pm 7.01^{\mathrm{c}}$ \\
\hline 30-39 years & 13 & $366.53 \pm 5.69^{\mathrm{a}, \mathrm{b}}$ & 10 & $329.06 \pm 6.15^{\mathrm{c}}$ \\
\hline $40-49$ years & 12 & $397.21 \pm 2.19^{\mathrm{a}, \mathrm{b}}$ & 13 & $360.31 \pm 6.98^{\mathrm{c}}$ \\
\hline $50-59$ years & 6 & $398.74 \pm 2.23^{\mathrm{a}, \mathrm{b}}$ & 4 & $383.26 \pm 6.14^{c}$ \\
\hline
\end{tabular}

${ }^{a}$ Significant differences $(p<0.05)$ between workers of palliative care and controls; ${ }^{b}$ significant differences $(p<0.05)$ among age groups in workers of palliative care; ${ }^{c}$ significant differences $(\mathrm{p}<0.05)$ among age groups in controls. MDA, malondialdehyde in $\mathrm{nmol} / \mathrm{mg}$ hemoglobin; $\mathrm{X} \pm \mathrm{DS}$, mean \pm standard deviation.

children. No difference was observed in SOD and CAT activities and MDA concentrations according to the place of birth.

\section{Lifestyle parameters}

Significant differences were detected (Table 3) in SOD1 and CAT activities and MDA concentrations between smokers and no smokers, but not for alcohol consumption, or coffee, tea and cola consumption.

Significant differences were obtained (Table 3) in MDA concentrations between those who frequently practice some kind of sport (279.91 $\pm 6.73 \mathrm{nmol} / \mathrm{mg}$ hemoglobin) and those who never practice sport $(299.12 \pm 8.09 \mathrm{nmol} / \mathrm{mg}$ hemoglobin).

With regard to consumption of fruits and greens, significant differences were seen (Table 3) in SOD1 activity $(\mathrm{p}<0.03)$ and MDA concentrations $(\mathrm{p}<0.01)$ between those who frequently eat fruits and greens and those who never ate fruits and greens.

\section{Occupational factors}

We found that SOD1 activity and MDA concentrations are higher in workers who work the night and evening shifts $(\mathrm{p}<0.01)$. We also observed that qualification and professional category had a stronger correlation with antioxidant enzyme activity and MDA concentrations. Likewise, long professional experience in a palliative care unit showed a relationship with respect to MDA and SOD1 activity. In general, professionals who had more years of professional experience showed higher values for two oxidative stress parameters.

Table 3 SOD1 and CAT activity and MDA concentrations according to sociodemographic and lifestyle parameters.

\begin{tabular}{|c|c|c|c|c|c|}
\hline Parameters & No. & SOD1 $(\mathrm{X} \pm \mathrm{DS})$ & $\mathrm{CAT}(\mathrm{X} \pm \mathrm{DS})$ & $\mathrm{MDA}(\mathrm{X} \pm \mathrm{DS})$ & $\mathrm{p}<$ \\
\hline \multicolumn{6}{|l|}{ Marital status } \\
\hline Single & 16 & $4.32 \pm 0.39$ & $234.09 \pm 4.16$ & $285.64 \pm 7.91$ & \multirow[t]{3}{*}{$\mathrm{p}<0.05^{\mathrm{a}}$} \\
\hline Married & 32 & $4.33 \pm 0.28$ & $237.32 \pm 5.11$ & $319.28 \pm 6.15^{\mathrm{a}}$ & \\
\hline Divorced & 4 & $4.35 \pm 0.09$ & $236.43 \pm 4.63$ & $289.04 \pm 5.88$ & \\
\hline \multicolumn{6}{|l|}{ Children } \\
\hline No children & 34 & $4.35 \pm 0.48$ & $233.76 \pm 6.48$ & $289.37 \pm 8.63$ & \multirow[t]{2}{*}{ No sig differ } \\
\hline With children & 28 & $4.37 \pm 0.23$ & $236.65 \pm 5.36$ & $294.15 \pm 8.11$ & \\
\hline \multicolumn{6}{|l|}{ Tobacco } \\
\hline Smokers & 15 & $4.38 \pm 0.42^{\mathrm{a}}$ & $236.23 \pm 3.68^{\mathrm{a}}$ & $326.08 \pm 5.49^{\mathrm{a}}$ & \multirow[t]{2}{*}{$\mathrm{p}<0.05^{\mathrm{a}}$} \\
\hline No smokers & 37 & $4.21 \pm 0.15$ & $227.85 \pm 3.27^{\mathrm{a}}$ & $287.45 \pm 6.10$ & \\
\hline \multicolumn{6}{|l|}{ Alcohol } \\
\hline Sometimes & 14 & $4.36 \pm 0.64$ & $238.07 \pm 5.13$ & $283.29 \pm 7.05$ & \multirow[t]{2}{*}{ No sig differ } \\
\hline Never & 38 & $4.36 \pm 0.53$ & $238.73 \pm 5.21$ & $287.42 \pm 8.23$ & \\
\hline \multicolumn{6}{|l|}{ Coffee, tea, cola } \\
\hline Time to time & 16 & $4.35 \pm 0.18$ & $238.29 \pm 4.15$ & $285.27 \pm 8.34$ & \multirow[t]{2}{*}{ No sig diffe } \\
\hline Habitually & 36 & $4.35 \pm 0.11$ & $238.81 \pm 5.02$ & $288.14 \pm 8.69$ & \\
\hline \multicolumn{6}{|l|}{ Sport } \\
\hline Frequently & 21 & $4.33 \pm 0.09$ & $236.11 \pm 5.69$ & $279.91 \pm 6.73$ & \multirow[t]{3}{*}{$\mathrm{p}<0.05^{\mathrm{a}}$} \\
\hline Sometimes & 26 & $4.31 \pm 0.18$ & $235.23 \pm 4.21$ & $286.35 \pm 6.14$ & \\
\hline Never & 5 & $4.30 \pm 0.38$ & $238.59 \pm 5.71$ & $299.12 \pm 8.09^{\mathrm{a}}$ & \\
\hline \multicolumn{6}{|l|}{ Fruits, greens } \\
\hline Frequently & 24 & $4.32 \pm 0.41$ & $233.78 \pm 5.11$ & $290.26 \pm 8.02$ & \multirow[t]{3}{*}{$\mathrm{p}<0.05^{\mathrm{a}}$} \\
\hline Sometimes & 22 & $4.33 \pm 0.38$ & $235.37 \pm 6.24$ & $297.32 \pm 6.98$ & \\
\hline Never & 6 & $4.38 \pm 0.53^{\mathrm{a}}$ & $237.51 \pm 5.16$ & $316.31 \pm 7.42^{\mathrm{a}}$ & \\
\hline
\end{tabular}

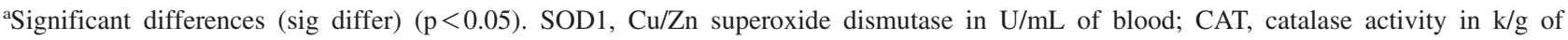
hemoglobin; MDA, malondialdehyde levels in nmol/mg hemoglobin; $\mathrm{X} \pm \mathrm{DS}$, mean \pm standard deviation. 
Table 4 Burnout levels and work shift in palliative care workers.

\begin{tabular}{llll}
\hline Shifts & $\begin{array}{l}\text { Morning } \\
(\mathrm{X} \pm \mathrm{DS})\end{array}$ & $\begin{array}{l}\text { Evening } \\
(\mathrm{X} \pm \mathrm{DS})\end{array}$ & $\begin{array}{l}\text { Night } \\
(\mathrm{X} \pm \mathrm{DS})\end{array}$ \\
\hline Numbers & 17 & 21 & 14 \\
Burnout & $35.34 \pm 4.74$ & $42.31 \pm 4.6^{\mathrm{a}}$ & $42.78 \pm 5.21^{\mathrm{b}}$ \\
EE & $13.68 \pm 2.83$ & $16.88 \pm 3.5^{\mathrm{a}}$ & $15.29 \pm 2.36$ \\
DP & $5.81 \pm 0.93$ & $7.32 \pm 0.7$ & $6.73 \pm 1.19$ \\
RPA & $15.39 \pm 3.19$ & $18.09 \pm 1.58^{\mathrm{a}}$ & $19.91 \pm 3.37^{\mathrm{b}}$ \\
\hline
\end{tabular}

${ }^{a}$ Significant differences between morning and evening shifts; ${ }^{\mathrm{b}}$ significant differences between morning and night shifts. $\mathrm{X} \pm \mathrm{DS}$, mean \pm standard deviation; EE, emotional exhaustion; DP, depersonalization; RPA, reduced personal accomplishment.

As far as factors that produce professional uneasiness, no significant differences were observed in workers in a palliative care unit with respect to oxidative stress parameters. These factors have been classified into: uneasiness produced by work conditions (lack of staff and resources), and institutional uneasiness caused by lack of promotion and information.

Significant variations in levels of burnout were detected with respect to professional category (burnout levels were: physicians $35.98 \pm 3.66$, nurses $42.87 \pm 4.09$ ). No relationship was detected with respect to age, gender and marital status. We found that burnout is higher in workers who work on the night and evening shifts. These workers also obtained higher scores in burnout subscales, with statistical significance (Table 4).

\section{Discussion}

Palliative care workers face the challenge of working closely and intensively with seriously ill patients and their families, which are highly emotional and stressful times in their lives. Palliative care workers often become deeply involved in the lives of their patients, many of whom die while under their care. Some medical disorders have higher prevalence in these workers. Nevertheless, the exact mechanisms of how such stress exerts these effects are not well-known. Stress could potentially lead to oxidative stress by increases in generation of ROS generation, or inactivation of enzymes which metabolize ROS, scavengers, and others substances that prevent their formation or help remove them.

In this work, as expected, the average perceived stress level was significantly higher in palliative care workers than in controls. MDA concentrations increase with age, supporting the premise that MDA is a valid marker of oxidative stress and aging. It is known that cell membrane structures are subjected to increased oxidative stress as a consequence of time and occupational stress. Inal et al. (26) also observed significantly higher concentrations in healthy individuals with respect to age. However, Di Rosa et al. (27) have not observed correlation of carbonylated and nitrosylated proteins, biomarkers of oxidative and nitrosative stress, respectively, with age in patients with adjustment disorders due to work stress.
We did not observe significant variations in SOD1 and CAT activities and MDA concentrations with respect to gender in workers in a hospital palliative care unit. These results agree with those obtained in a Spanish population (23-25) working in emergency service $(2,3)$, and in nurses in an intensive care unit (4).

Marital status has an influence on oxidative stress levels because married workers showed higher MDA concentrations compared with single or divorced workers, but no significant differences were observed with regard to having children or to the number of children. These results agree with those obtained in emergency workers (3). De la Torre et al. (23) observed significant differences according to place of birth (urban or rural). However, in this work we did not observe any difference because all subjects had been living in a big city for many years.

With respect to the effects of cigarette smoking, we found that SOD1 and CAT activities and MDA concentrations were higher in the erythrocytes of smokers compared with nonsmokers $(p<0.05)$. One possible explanation of this fact is that cigarette smoking increases oxygen free radical production by polymorphonuclear leucocytes, which induce the activation of some free radical scavengers, such as SOD, CAT or GPx. However, if antioxidant enzyme activities are deficient, this can lead to oxidative stress and cellular membrane damage. Similar results were obtained by Bolzan et al. (28) and Diken et al. (29). Our results agree with those obtained in smokers by Özbay and Dülger (30) who observed that smoking led to higher MDA concentrations and lower SOD activity. Tobacco smoke contains numerous compounds, many of which are oxidants and pro-oxidants that are capable of producing free radicals and enhancing the oxidative stress "in vivo".

With respect to physical exercise, Davies et al. (31) reported that exercise at high intensity causes increased free radical production. However, regular physical exercise enhances the antioxidant system and protects against exercise induced free radical damage. In this study, when subjects practiced regular physical activity, there was an insignificant increase in MDA concentrations, and SOD1 and CAT activities. However, when subjects never exercised, we observed a significant reduction in SOD1 and CAT activities, and an increase in MDA concentrations. Regular exercise has a variety of psychological benefits than can help to improve mental health (32), reducing the risk of disease $(33,34)$ and slows down aging (35). In addition, regular exercise can help to relieve occupational stress.

Although alcohol has the ability to generate formation of ROS which are able to start lipid peroxidation, either directly or by exhausting antioxidative defense substances, in this work no significant differences in MDA concentrations related to consumption of alcohol, coffee, tea or cola. Also, differences in antioxidant enzyme activities could be demonstrated. The reason for this fact was the moderate alcohol consumption of the participants in this study. No significant differences in MDA concentrations or antioxidant enzyme activities related to consumption of alcohol, coffee, tea or cola could be demonstrated. These results agree with those 
obtained by Casado et al. $(2,3)$ in emergency service workers and in nurses in an intensive care unit (4). Nielsen et al. (36) found a positive correlation between plasma MDA and weekly alcohol consumption. However, in our study, alcohol consumption of the participants analyzed included only small quantities that was consumed during meals. This practice has certain proven beneficial effects in humans, and epidemiological evidence indicates that moderate alcohol consumption reduces the incidence of heart disease $(37,38)$.

No significant variation in burnout levels were obtained with respect to age, gender and marital status. Our findings agree partially with those obtained by Smith et al. (39) who observed no significant difference between men and women with respect to occupational stress, and that unmarried and married workers reported very similar stress levels. However, we detected higher oxidative stress in married workers than in unmarried or divorced workers, and similar results were obtained in emergency workers (3). The results obtained by Geetika (40) revealed that male nurses experienced significantly higher stress level compared to females.

The biological mechanisms responsible for how shift work acts to induce such disorders in workers are relatively unknown. The known mechanism that induces and promotes cellular damage and results in such disorders is known as oxidative stress. Ishihara et al. (41) examined the effect of occupational stress on oxidative DNA damage among female workers. They found that female workers in shift work excreted increased levels of 8-hydroxydeoxyguanosine compared with those who were engaged in part time work $(p<0.01)$. We showed that burnout is higher in workers on evening and night shifts. These workers also obtained significantly higher scores in burnout subscales. Purvi et al. (42) also showed that shift work is prevalent among nurses and a significant source of stress. They found that this type of work results in higher SOD1 activity and MDA concentrations in workers who work the night and evening shifts $(\mathrm{p}<0.01)$. Similar results were obtained in emergency service workers $(2,3)$. Sharifian et al. (43) evaluated the effect of night shift work, and their results confirm that shift work can act as an oxidative stressor. Furthermore, Dahlgren et al. (44) found a significant association between workday starting times and finishing times and cortisol concentrations. Those that finished their workday late had high concentrations of cortisol in the evening and low concentrations the following morning.

With respect to professional category, significant differences $(p<0.05)$ were detected in burnout levels between physicians and nurses. These results agree with those obtained by Bujalance Hoyos et al. (45) and Olley (46).

\section{Conclusions}

In conclusion, our findings suggest that oxidative stress, occupational stress and burnout levels are similar in men and women. Occupational stress increases oxidative stress levels, probably as a response to increased generation of ROS. Working the evening and night shifts increase oxidative lev- els and burnout levels. It is evident that preventive changes in job conditions and lifestyle are necessary to improve the quality of life for workers who work in palliative care units.

\section{Acknowledgments}

We are grateful to the personnel of the palliative care units, and the control individuals, for their participation in this study. These studies were performed with funds provided by the Yebenes Velo Foundation. The authors express their gratitude to Miss María Burgos, for her excellent reviewing of English in this manuscript.

\section{Conflict of interest statement}

Authors' conflict of interest disclosure: The authors stated that there are no conflicts of interest regarding the publication of this article. Research funding played no role in the study design; in the collection, analysis, and interpretation of data; in the writing of the report; or in the decision to submit the report for publication.

Research funding: None declared.

Employment or leadership: None declared.

Honorarium: None declared.

\section{References}

1. Hemnani T, Parihar MS. Reactive oxygen species and oxidative DNA damage. Indian J Physiol Pharmacol 1998;42:440-52.

2. Casado Moragón A, De Lucas García N, López-Fernández ME, Sánchez Rodríguez-Manzaneque A, Jiménez Fraile JA. Antioxidant enzymes, occupational stress and burnout in workers of a prehospitalary emergency service. Eur J Emerg Med 2005; $12: 111-5$.

3. Casado A, De Lucas N, López-Fernández ME, Sánchez A, Jiménez JA. Lipid peroxidation, occupational stress and aging in workers of a prehospital emergency service. Eur J Emerg Med 2006;13:164-71.

4. Casado A, Castellanos A, López-Fernández E, Ruiz R, García Aroca C, Noriega F. Relationship between oxidative and occupational stress and aging in nurses of an intensive care unit. AGE 2008;30:229-36.

5. Halliwell B, Gutteridge JM. Free radicals in biology and medicine. Oxford: Claredon Press, 1985.

6. Freeman BA, Crapo JD. Biology of disease, free radicals and tissue injury. Lab Invest 1982;47:412-26.

7. Gardner HW. Decomposition of linoleic acid hydroperoxides. Enzymic reactions compared with nonenzymic. J Agr Food Chem 1975;23:129-36.

8. Draper HH, Dhanakoti SN, Hadley M, Piche LA. Malondialdehyde in biological systems. In: Chow CK, editor. Cellular antioxidant defense mechanism. Boca Raton, FL: CRC Press 1988:97-100.

9. Esch T. Health in stress: change in the stress concept and in significance for prevention, health and life style. Gesundheiswesen 2002;64:73-81.

10. Jezová D, Kristova V, Slamova J, Mlynarik M, Pirnik Z, Kiss A, et al. Stress-induced rise endothelaemia, von Willebrand factor and hypothalamic-pituitary-adrenocortical axis activation is reduced by pre-treatment with pentoxifylline. J Physiol Pharmacol 2003;54:329-38. 
11. Holmes A, Heilig M, Rupniak NM, Steckler T, Griebel G. Neuropeptide systems as novel therapeutic targets for depression and anxiety disorders. Trends Pharmacol Sci 2003;24:580-8.

12. Black PH. The inflammatory response is an integral part of the stress response: implications for atherosclerosis, insulin resistance, type II diabetes and metabolic syndrome X. Brain Behav Immun 2003;17:350-64.

13. Maslach C, Jackson SE. Maslach Burnout Inventory manual, 3rd ed. Palo Alto, CA: Consulting Psychological Press, 1996.

14. McGrath A, Reid N, Boore J. Occupational stress in nursing. Int J Nurs Stud 2003;40:555-65.

15. Duane Akroyd RT, Amy Caison MS, Robert Adams RT. Burnout in radiation therapist: the predictive value of selected stressors. Int J Radiat Oncol 2002;52:816-21.

16. Minami M, Yoshikawa H. A simplified assay method of superoxide dismutase activity for clinical use. Clin Chim Acta 1979; 92:337-42.

17. McCord JM, Fridovich I. Superoxide dismutase: an enzymic function for erythrocuprein (hemocuprein). J Biol Chem 1969; 244:6049-55.

18. Aebi H. Catalase. In: Bergmeyer HU, editor. Methods of enzymatic analysis. New York: Academic Press, 1974:673-83.

19. Bull AW, Marnett LJ. Determination of malondialdehyde by ion-pairing high-performance liquid chromatography. Anal Biochem 1985;149:284-90.

20. Esterbauer H, Lang J, Zadravec S, Slater F. Detection of malondialdehyde by high-performance liquid chromatography. In: Packer L, editor. Methods in enzymology: oxygen radical in biological systems. London: Academic Press, 1984;105:31927.

21. Drabkin DL, Austin JH. Spectrophotometric studies: spectrofotometric constants for common haemoglobin derivatives in human, dog and rabbit blood. J Biol Chem 1932;98:719-23.

22. Oliver C. Stress in helping professions. Burnout as a specific syndrome. Thesis Doctoral. Universidad Autónoma de Madrid, 1993.

23. De la Torre MR, Casado A, López-Fernández ME. Superoxide dismutase activity in the Spanish population. Experientia 1990; 46:854-6.

24. Casado A, López-Fernandez ME. Age-correlated changes of the erythrocyte catalase activity in the Spanish population. Gerontology 2003;49:251-4.

25. Gil P, Fariñas F, Casado A, López-Fernández ME. Malondialdehyde: a possible marker of ageing. Gerontology 2002;48: 209-14.

26. Inal ME, Kanbak G, Sunal E. Antioxidant enzyme activities and malondialdehyde levels related to aging. Clin Chim Acta 2001;305:75-80.

27. Di Rosa AE, Gangemi S, Cristani M, Fenga C, Saitta S, Abenavoli E, et al. Serum levels of carbonylated and nitrosylated proteins in mobbing victims with workplace adjustment disorders. Biol Psychol 2009;82:308-11.

28. Bolzan AD, Bianchi MS, Bianchi NO. Superoxide dismutase, catalase and glutathione peroxidase activities in human blood: influence of sex, age and cigarette smoking. Clin Biochem 1997;30:449-54.

29. Diken H, Kelle M, Tümer C, Deniz B, Baylan Y, Sermet A. Effects of cigarette smoking on blood antioxidant status in short-term and long-term smokers. Turk J Med Sci 2001;31: $553-7$.

30. Özbay B, Dülger H. Lipid peroxidation and antioxidant enzymes in Turkish population: relation to age, gender, exercise and smoking. Tohoku J Exp Med 2002;197:110-24.

31. Davies KJ, Quintanilla AT, Brooks GA, Parker L. Free radicals and tissue damage produced by exercise. Biochem Biophys Res Commun 1882;107:1198-205.

32. Goodwin RD. Association between physical activity and mental disorders among adults in the United States. Prev Med 2003; 36:698-703.

33. Kwak YS, Um SY, Son TG, Kim DJ. Effect of regular exercise on senile dementia patients. Int J Sports Med 2008;29:471-4.

34. Maruti SS, Willett WC, Feskanich D, Rosner B, Colditz GA. A prospective study of age-specific physical activity and premenopausal breast cancer. J Natl Cancer Inst 2008;100:728-37.

35. Cherkas LF, Hunkin JL, Kato BS, Richards JB, Gadner JP, Surdulesco GL, et al. The association between physical activity in leisure time and leukocyte telomere length. Arch Intern Med 2008; $168: 154-8$.

36. Nielsen F, Mikkelsen BB, Nielsen JB, Andersen HR, Grandjean P. Plasma malondialdehyde as biomarker for oxidative stress: reference interval and effects of life-style factors. Clin Chem 1997;43:562-8.

37. Eidelman RS, Vignola P, Hennekens CH. Alcohol consumption and coronary heart disease: a causal and protective factors. Sem Vas Med 2002;2:253-6.

38. Abou-Agap LH, Khoo NK, Binsack R, White CR, DarleyUsmar V, Grenett HE, et al. Evidence of cardiovascular protection by moderate alcohol: role of nitric oxide. Free Radic Biol Med 2005;39:540-8.

39. Smith A, Brice C, Collins A, Matthews V, McNamara R. The scale of occupational stress: a further analysis of the impact of demographic factors and type of job. HSB Books Contract Research Report 311/2000, 2000.

40. Geetika T. A comparative study of role stress in government and private hospital nurses. J Health Manag 2004;8:11-22.

41. Ishihara I, Nakano M, Ikushima M, Hara Y, Yoshimine T, Haraga $\mathrm{M}$, et al. Effect of work conditions and work environments on the formation of $8-\mathrm{OHdG}$ in nurses and no nurse female workers. J UOEH 2008;30:293-308.

42. Purvi P, Atish T, Tanmay B. Occupational stress and coping among nurses. J Health Manag 2004;6:115-27.

43. Sharifian A, Farahani S, Pasalar P, Gharavi M, Aminian O. Shift work as an oxidative stressor. J Circadian Rhytms 2005;3: 15-7.

44. Dahlgren A, Kecklund G, Theorell T, Akerstedt T. Day-to-day variation in saliva cortisol-relation with sleep, stress and selfrated health. Biol Psychol 2009;2:149-55.

45. Bujalance Hoyos J, Villanueva Pardo F, Guerrero Manzano S, Conejo García J, González Valentín A, Sepúlveda Jurado A, et al. Burnout y satisfacción laboral de los profesionales que atienden a pacientes geriátricos. Rev Esp Geriatr Gerontol 2001;6: 32-40.

46. Olley BO. A comparative study of burnout syndrome among health professionals in a Nigerian teaching hospital. Afr J Med Med Sci 2003;2:297-302. 